\title{
TẦN SUẤT, ĐĂC ĐIỂM LÂM SÀNG, CÂN LÂM SÀNG CỦA CƠ'N CẤP MẤT BÙ BETA-KETOTHIOLASE TẠI BỆNH VIỆN NHI TRUNG ƯƠNG
}

\section{TÓM TẮT}

Mục tiêu 1. Xác định tân suất, đăc điểm lâm sàng, cận lâm sàng của cơn cấp mất bù bệnh thiếu beta-ketothiolase. Đối tượng nghiên cứu: 23 đối tương được chẩn đoán và điều tri tai bênh viên Nhi Trung ương từ tháng 1/2015 đến 6/2021. Phương pháp: Nghiên cứu mô tả. Kết quả: $95,3 \%$ bênh nhân xuất hiện cơn cấp mất bù, tuổi xuất hiện cơn cấp chủ yếu dưới 12 tháng, trung bình một bệnh nhân xuất

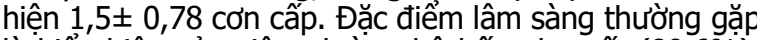
là biểu hiê̂n của viêm đường hô hấp như sốt $(80,6 \%)$, ho $(72,2 \%)$, nôn $(69,4 \%)$ sau đó đi vào rối loạn tri giác $(72,2 \%)$. Đắc điểm cân lâm sàng: $91,6 \%$ bềnh nhân đều có ceton niệu trong các cơn cấp mất bù, hầu hết bênh nhân đều có hiên tượng tăng toan chuyển hóa chiếm $86,1 \%$. Xét nghiệm định lượng acyl-carnitin tăng 2-methyl-3hydroxybutyrylcarnitine (C5:1) chiếm $82,6 \%$, tăng tiglylcarnitine $(\mathrm{C} 5: \mathrm{OH})$ chiếm $86,9 \%$. Xét nghiệm định lượng acid hữu cơ chủ yếu tăng 2methyl-3-hydroxylbutyryl (2M3HB) chiểm 95\%. Kết luận: Tần suất xuất hiện cơn cấp mất bù tương đối cao chiếm 95,3\%. Đa số các bênh nhân có triêu chứng của viêm nhiễm đường hô hấp như sốt, ho, rồi đi vào li bì, hôn mê, xét nghiệm tăng $\mathrm{C} 5: 1$ và $\mathrm{C} 5: \mathrm{OH}$ và $2 \mathrm{M} 3 \mathrm{HB}$ là chủ yếu.

Tư khóa: Bênh thiếu beta-ketothiolase, C5: $\mathrm{OH}$ (tiglylcarnitine), C5: 1(2-methyl-3hydroxybutyrylcarnitine), 2MAA (2-methylacetoacetyl), 2M3HB (2-methyl-3hydroxylbutyryl), TIG (tiglylcarnitine), định lượng acid hữu cơ niệu, định lượng acyl-carnitin.

\section{SUMMARY}

FREQUENCY, THE CLINICAL AND BIOCHEMICAL FEATURES OF ACUTE DECOMPENSATED EPISODE WITH BETAKETOTHIOLASE DEFICIENCY IN VIETNAM NATIONAL CHILDREN'S HOSPITAL

Objective: Frequency, the clinical and biochemical features acute decompensated episode with betaketothiolase deficiency. Subject: A total of 23 children betaketothiolase deficiency were diagnosed treated and monitored in the Vietnam National Children's Hospital from January 2015 to June 2021. Method: Descriptive study. Results: $95.3 \%$ of patients had acute decompensated episode, the age of onset was mainly less than 12 months, on average, one patient had $1.5 \pm 0.78$ acute attacks. Common

${ }^{1}$ Đại học Y Hà Nội

²Bệnh viện Nhi Trung Uơng

Chịu trách nhiệm chính: Nguyễn Ngọc Khánh

Email: bsthunhitb@gmail.com

Ngày nhận bài: 14.5.2021

Ngày phản biên khoa họ: 30.6.2021

Ngày duyệt bài: 13.7.2021 clinical features are respiratory tract inflammation such as fever $(80.6 \%)$, cough $(72.2 \%)$, vomiting $(69.4 \%)$ and then go into mental disorder $(72,5 \%)$. Biochemical characteristics: $91.6 \%$ of patients had ketonuria during acute decompensation episodes, the majority of patients with metabolic acidosis accounted for $86.1 \%$. Plasma acyl-carnitin profile revealed increased C5: 1 accounted for $82.6 \%$, increased C5: $\mathrm{OH}$ accounted for $86.9 \%$. Urinary organic acids profile revealed mainly increased by $2 \mathrm{M} 3 \mathrm{HB}$, accounting for $95 \%$. Conclusion: The frequency of acute decompensation accounted for $95.3 \%$. Most patients had symptoms of respiratory infection such as fever, cough, then coma, plasma acyl-carnitin profile revealed increased $\mathrm{C} 5$ : 1 and $\mathrm{C} 5$ : $\mathrm{OH}$. Urinary organic acids profile revealed mainly increased by $2 \mathrm{M} 3 \mathrm{HB}$.

\section{I. ĐẶT VẤN ĐỀ}

Bệnh thiếu beta-ketothiolase (BKT) là bệnh di truyền lặn trên nhiễm sắc thể thường do đột biến gen T2 (ACAT1) nằm trên cánh dài nhiễm sắc thể số 11(11q22.3-q23.1) mã hóa gen tạo ra Acetoacetyl Coa thiolase hay còn gọi là BKT. BKT là enzym xúc tác quá trình chuyển hóa isoleucine và ceton trong cơ thể [1].

Bệnh thiếu BKT hay gặp các cớn cấp mất bù đặc trưng bởi những đợt nhiễm toan ceton không triệu chứng lâm sàng giữa các cơn. Tần suất cơn cấp mất bù theo nghiên cứu của tác giả Fukao trên 24 bệnh nhân tương đối cao khoảng $88 \%$ [1]. Các cởn cấp mất bù bênh thiếu BKT thường xuất hiện sau khi trẻ bị nhiễm trùng hô hấp, viêm ruột ...hoặc ăn quá nhiều protein. Triệu chứng trong cơn cấp mất bù thường thấy: li bì, bỏ bú, nôn co giật hôn mê, hoặc tình trạng sốc nặng....Bênh cảnh cơn cấp mất bù dễ chẩn đoán nhầm với các bệnh khác như xuất huyết não, viêm não màng não, sốc nhiễm trùng ...[2][3].

Các cơn cấp mất bù của bệnh thiếu BKT nếu không được chẩn đoán và điều trị kịp thời, bênh nhân có thể tử vong hoặc để lại di chứng nặng về phát triển tâm thần vận động.

Việc nghiên cứu cơn cấp mất bù là cơ sở khoa học giúp đánh giá một cách toàn diên về tình trang sức khỏe từ đó đưa ra các biện pháp phòng tránh cơn cấp mất bù và điều điều trị phù hợp với bệnh nhân vì vậy chúng tôi tiến hành nghiên cứu này với mục tiêu: "Xác định tần suất, đặc điểm lâm sàng, cận lâm sàng của cơn cấp mất bù bệnh thiếu beta-ketothiolase tại bệnh viện Nhi Trung ương." 
II. ĐỐI TƯỢNG VÀ PHƯƠNG PHÁP NGHIÊN CỨU

2.1. Đối tượng nghiên cứu: 23 bệnh nhân được chẩn đoán thiếu BKT tại bệnh viện Nhi Trung ương từ tháng 1/2005 đển 6/2021

Tiêu chuẩn chọn mẫu: Tất cả bệnh nhân được chẩn đoán xác định bệnh bằng xét nghiệm thấy tăng $2 \mathrm{MAA}, 2 \mathrm{M} 3 \mathrm{HB}$, TIG niệu bằng phương pháp định lượng acid hữu cơ niệu và/hoặc có đột biến gen $\mathrm{T} 2$ gây bệnh.

Tiêu chuẩn bệnh nhân cơn cấp mất bù: Bệnh nhân được chẩn đoán bệnh thiếu BKT, bệnh nhân vào viện trong tình trạng mệt mỏi, kích thích, li bì, xét nghiệm có tình trạng toan chuyển hóa hoặc có ceton trong nước tiểu.

Tiêu chuẩn loại trừ: Gia đình trẻ và trẻ không đồng ý tham gia nghiên cứu

2.2. Phương pháp nghiên cứu: Mô tả một loạt ca bệnh

Thời gian nghiên cứu: tháng 2005 đến tháng 06/2021 tại Bệnh viện Nhi Trung ương.

Các biến số nghiên cứu: tuổi, giới, tiền sử gia đình, nghề nghiệp bố mẹ, tần suất cơn cấp mất bù, đặc điểm lâm sàng, đặc điểm cận lâm sàng.

Xử lý số liệu: theo thuật toán thống kê $Y$ học trung vị, trung bình, độ lệch chuẩn, tỷ lệ theo phần mềm SPPSS 20.0.

\section{KẾT QUẢ NGHIÊN CỨU}

\section{1. Đặc điểm của đối tượng nghiên cứu}

Bảng 3.1: Đặc điểm chung của đối tượng nghiên cứu

\begin{tabular}{|c|c|c|c|c|c|c|c|}
\hline \multirow{2}{*}{$\begin{array}{l}\text { Trung vị } \\
\text { (Min-Max) (tháng) }\end{array}$} & \multicolumn{2}{|c|}{ Giới } & \multicolumn{4}{|c|}{ Nghề nghiệp của bố mẹ } & \multirow{2}{*}{$\begin{array}{l}\text { Bố mé cùng } \\
\text { huyết thống }\end{array}$} \\
\hline & Nam & Nữ & $\begin{array}{l}\text { Nông } \\
\text { dân }\end{array}$ & $\begin{array}{l}\text { Công } \\
\text { nhân }\end{array}$ & $\begin{array}{c}\text { Trí } \\
\text { thức }\end{array}$ & Khác & \\
\hline $\begin{array}{c}43 \\
(7-177) \\
\end{array}$ & $\begin{array}{c}39,1 \\
(9)\end{array}$ & $\begin{array}{l}60,9 \\
(14)\end{array}$ & $\begin{array}{c}30,4 \% \\
(7)\end{array}$ & $\begin{array}{l}30,4 \% \\
(7)\end{array}$ & $\begin{array}{l}21,7 \% \\
(5)\end{array}$ & $\begin{array}{l}17,5 \% \\
(4)\end{array}$ & \\
\hline
\end{tabular}

Nhận xét: Tuối bệnh nhân từ 7 tháng đến 177 tháng trung vị 43 tháng, đa số là nữ chiếm $60,9 \%$, nghề nghiệp của bố hoăc mẹ bệnh nhân phần lớn là công nhân và nông dân chiếm $30,4 \%$.

\subsection{Tân suất cớn cấp mất bù}

\section{Bảng 3.2. Tần suất cớn cấp mất bù}

\begin{tabular}{|c|c|c|c|c|c|}
\hline & \multirow{4}{*}{$\begin{array}{c}\text { Số cơn cấp mất } \\
\text { bù / bệnh nhân } \\
1,5 \pm 0,78 \\
(1-3)\end{array}$} \\
\hline Tân suất cơn & ấp mất bù & Tuổi xuá & hiện cơn cấ & mất bù & \\
\hline Không xuất hiện & Có xuất hiện & $<12$ tháng & 12-36 tháng & $>36$ tháng & \\
\hline $95,3 \%(22)$ & $4,3 \%(1)$ & $55,5 \%(20)$ & $36,1 \%(13)$ & $8,4 \%(3)$ & \\
\hline
\end{tabular}

Nhận xét: Tần xuất cơn cẫp mất bù bệnh thiếu BKT là $95,3 \%$. Tuối xuất hiện cơn cấp mất bù đa số < 12 tháng. Số cơn cấp mất bù $1,5 \pm 0,78$.

\section{3. Đặc điểm cơn cấp mất bù \\ Bảng 3.3. Đặc điểm lâm sàng cơn câp} mất bù

\begin{tabular}{|c|c|c|}
\hline Đặc điếm & $\mathbf{N}$ & Tỷ lệ $\%$ \\
\hline Sốt & $29 / 36$ & 80,6 \\
\hline Ho & $26 / 36$ & 72,2 \\
\hline Nôn & $25 / 36$ & 69,4 \\
\hline Tiêu chảy & $15 / 36$ & 41,6 \\
\hline Thay đối tri giác & $26 / 36$ & 72,2 \\
\hline
\end{tabular}

Nhận xét: Trong các triệu chứng lâm sàng thường gặp trong cơn cấp mất bù bênh thiếu BKT, triệu chứng phổ biến nhất là sốt chiếm $80,6 \%$. Sau đó đến ho và thay đổi tri giác chiếm $72,2 \%$.

Bảng 3.4. Đặc điểm cận lâm sàng cơn câp mất bù

\begin{tabular}{|c|c|c|c|}
\hline \multicolumn{2}{|c|}{ Xét nghiệm } & $\mathbf{N}$ & Tỷ lệ \% \\
\hline \multirow{3}{*}{$\begin{array}{c}\text { Xét nghiêm } \\
\text { lâm sàng } \\
\text { thường quy }\end{array}$} & Toan chuyến hóa & $31 / 36$ & 86,1 \\
\cline { 2 - 4 } & Hạ glucộu & $33 / 36$ & 91,6 \\
\cline { 2 - 4 } & Tăng amoniac & $3 / 36$ & 8,3 \\
\cline { 2 - 4 } & Tăng bạch cầu & $14 / 36$ & 5,5 \\
\hline Oịnh lượng & Tăng C5:OH & $20 / 23$ & 86,9 \\
\hline
\end{tabular}

\begin{tabular}{|c|c|c|c|}
\hline acyl-carnitin & Tăng C5:1 & $19 / 23$ & 82,6 \\
\hline Eịnh lượng & Tăng 2MAA & $7 / 23$ & 30,4 \\
\cline { 2 - 4 } $\begin{array}{c}\text { axit hứu cớ } \\
\text { niệu }\end{array}$ & Tăng 2M3HB & $22 / 23$ & 95,6 \\
\cline { 2 - 4 } & Tăng TIG & $16 / 23$ & 69,5 \\
\hline
\end{tabular}

Nhânn xét: Trong các triệu chứng cận lâm sàng thường quy (toan chuyển hóa, ceton niệu, hạ glucose, tăng ammoniac, tăng bạch cầu) triệu chứng hay gặp nhất là ceton niệu chiếm $91,6 \%$, sau đó đến toan chuyển hóa chiếm $86,1 \%$. Trong các xét nghiệm sinh hóa đặc hiệu đa số các bệnh nhân đều có tăng $2 \mathrm{M} 3 \mathrm{HB}$ (định lượng acid hữu cơ niệu), sau đó đến tắng $\mathrm{C} 5: 1$ và C5:OH (định lượng acyl-carnitin).

\section{BÀN LUẬN}

4.1. Đặc điểm chung của đối tượng nghiên cứu. Trong 23 bệnh nhân được chẩn đoán bệnh thiếu BKT có tuổi của bệnh nhân trung vị 43 tháng, trong đó bệnh nhân bé tuổi nhất là 7 tháng, bệnh nhân lớn tuổi nhất lớn tuổi nhất là 177 tháng.

Theo nghiên cứu của chúng tôi tỷ lệ bị bệnh 2 
giới nam và nữ lần lượt là $39,1 \%$ và $60,9 \%$. Trong khi các nghiên cứu khác chỉ ra rằng tỉ lệ bị bệnh ở 2 giới tương đương nhau [4]. Sự khác nhau này có lẽ là do cách lấy mẫu.

Nghề nghiệp của bố mẹ chủ yếu là là công nhân và nông dân điều này là hoàn toàn hợp lý vì nông dân và công nhân là nghề nghiệp chiếm đa số trong dân số Viêt Nam.

4.2. Tân xuất xuất hiện cơn cấp tái phát. Tần xuất xuất hiện cơn cấp mất bù chiếm 95,3\%, không xuất hiện cơn cấp chiếm 4,3\%. Một bệnh nhân không xuất hiện cơn cấp được chẩn đoán chương trình qua sàng lọc sơ sinh và được theo dõi điều trị thường xuyên. Nghiên cứu này tương tự với nghiên cứu của tác giả Nguyễn Ngọc Khánh, tỷ lệ xảy ra cơn cấp mất bù là $93 \%$, không xảy ra cơn cấp khoảng $7 \%$ [4], khác với nghiên cứu của Fukao [1] tần suất không xảy ra cơn cấp là $11 \%$, sự khác nhau này là do 2 nghiên cứu này diễn ra ở 2 địa điểm khác nhau và thời gian nghiên cứu cũng khác nhau.

Tuổi xuất hiện cơn cấp mất bù: Đa số bệnh nhân xuất hiện cơn cấp mất bù thuộc nhóm tuổi dưới 12 tháng chiếm 55,5\%, tần xuất xuất hiện cơn cấp giảm dần khi tuổi trẻ càng cao. Điều này có thể giải thích trẻ nhỏ tuổi nhu cầu năng lượng so với cân nặng là nhiều hơn so với trẻ lớn, sự phân bố lớp mõ̃ dưới da nhiều, năng lượng dự trữ chủ yếu từ lớp mõ dự trữ trong khi đối với trẻ lớn thì lớp mõ dưới da ít thay vào đó là lớp cơ nên năng lượng dự trữ được lấy từ protein dự trữ, tần xuất các bữa ăn ngắn hơn nên trẻ nhỏ dễ xảy ra các cơn cấp hơn trẻ lớn. Nghiên cứu của chúng tôi khác với nghiên cứu của tác giả FuKao tuổi xuất hiện cơn cấp mất bù thường 618 tháng [5].

Cơn cấp mất bù: Theo nghiên cứu của chúng tôi số cơn cấp mất bù trên một bệnh nhân $1,5 \pm$ 0,78 (1-3). Đặc điểm này giống với nghiên cứu của tác giả Nguyễn Ngọc Khánh và cộng sự đa số bệnh nhân đều số cơn cấp mất bù là 1 và 2 [4].

4.3. Đặc điểm lâm sàng của cơn cấp mất bù. Bệnh thiếu BKT hay gặp các cơn cấp mất bù đặc trưng bởi những đợt nhiễm toan ceton không triệu chứng lâm sàng giữa các cơn. Trong 22 bệnh nhân có biểu hiện cơn cấp mất bù hầu hết bệnh nhân có biểu hiện của đường hô hấp như sốt $(80,6 \%)$, ho $(72,2 \%)$, nôn $(69,4 \%)$ sau đó đi vào rối loạn tri giác $(72,2 \%)$, chính vì vậy bệnh nhân khi được vào viện thường được chẩn đoán sơ bộ là viểm phổi nặng, tiêu chảy cấp, viêm màng não...kết quả nghiên cứu này giống của tác giả Fukao[1],[6].

4.4. Đặc điểm cận lâm sàng của bệnh nhân betaketo-thiolase. Trong nghiên cứu của chúng tôi $91,6 \%$ bệnh nhân đều có ceton niệu trong các cơn cấp mất bù, hầu hết bệnh nhân đều có hiện tượng toan chuyển hóa chiếm $86,1 \%$ lý do là thiếu BKT làm gián đoạn quá trình giáng hóa isoleucine dẫn tới ứ đọng 2 methylacetoacetyl-CoA, 2 methyl-3-hydrobutyrylCoA, tigglyl-CoA do không giáng hóa được thành Acetyl-CoA và Propionyl-CoA. Đông thời làm tăng các thể ceton 3hydroxylbutyrat, AcAc do không giáng hóa gây nhiễm toan ceton. Tỉ lệ bệnh nhân có tăng bạch cầu là $38,8 \%$ phản ánh tình trạng nhiễm trùng. Đây chính là nguyên nhân gây khởi phát cơn cấp mất bù. Nghiên cứu này giống với nghiên cứu của tác giả FuKao và cộng sự [7], Nguyễn Ngọc Khánh và cộng sự [6].

Xét nghiệm hoá sinh đặc hiệu của bệnh rối loạn chuyển hóa bảm sinh thiếu enzym BKT là phân tích acid hữu cơ niệu và phân tích acylcarnitine máu. Trong đó, phân tích acid hữu cơ niệu có giá trị đặc hiệu hơn trong chẩn đoán bệnh thiếu enzym BKT và phân tích acylcarnitine máu có giá trị trong sàng lọc sơ sinh. Ba dấu ấn trong nước tiểu đặc hiệu cho bệnh thiếu enzym BKT là 2MAA, 2M3HB, TIG. Hai dấu ấn điển hình cho bệnh thiếu enzym BKT trong máu là $C 5: 1$ và $\mathrm{C} 5: \mathrm{OH}$.

Đa số các bệnh nhân đều có tăng $C 5: 1$ và $\mathrm{C} 5: \mathrm{OH}$, tuy nhiên vẫn có 3 bệnh nhân xét nghiệm $\mathrm{C} 5: 1$ và $\mathrm{C} 5: \mathrm{OH}$ bình thường ngay cả trong cơn cấp. Điều này ủng hộ việc đưa phân tích acylcarnitin máu bằng phương pháp Tandem Mass vào sàng loc sơ sinh bệnh thiếu $B K T$.

Trong xét nghiệm phân tích acid hữu cơ niệu tỷ lệ phát hiện 2 MAA là ít nhất lý do Bởi vì $2 M A A$ là chất không ổn định trên giây thấm và giáng hoá tự nhiên thành 2-butanon sau 1 tuần ở nhiệt độ phòng nên 2MAA sẽ không phát hiện được trên các mẫu bệnh phẩm giây thấm nước tiểu. Trong khi đó đa số bệnh nhân phát hiện tăng 2M3HB (95\%). Kết quả của nghiên cứu này tương tự nghiên cứu của FuKao và cộng sự [5].

\section{KẾT LUÂ̂N}

Bênh thiễu BKT là bênh rối loạn chuyển hóa bẩm sinh thường gặp, có tần suất xuất hiện cơn cấp mất bù cao chiếm $95,3 \%$. Đa số các bệnh nhân có triêu chứng của viêm nhiễm đường hô hấp như sốt, ho, rồi đi vào li bì, hôn mê, định lượng acyl- carnitin tăng $\mathrm{C} 5: 1$ và $\mathrm{C} 5: \mathrm{OH}$, định lượng acid hữu cơ niệu tăng $2 \mathrm{M} 3 \mathrm{HB}$ là chủ yếu.

\section{TÀI LIỆ THAM KHẢO}

1. FuKao T (2001). Beta- keto dificiency. Ophanet encyclopedia, 1-11. 
2. Nguyễn Thu Nhạn (2020). Bệnh thiếu betaketothiolase.Bênh nội tiết chuyển hóa di truyền trẻ em. Nhà xuất b̉ản Y hoc, Hà Nôii, 307-313.

3. Hampe M.H, Panaskar S.N, Yadav A.A et al (2017). Gaschromatography/mass spectrometrybased urine metabolome study in children for inborn errors of metabolism: An Indian experience. Clinical Biochemistry, 50(3), 121-126.

4. Nguyễn Ngọc Khánh (2017). Nghiên cứu kiểu gen kiểu hình và kết quả điều trị bệnh thiếu enzym beta-ketothiolase ở Việt Nam, Luận án tiến sỹ y học, Đại học Y Hà Nôii.

5. Fukao $T$, Sasai $H$, Aoyama $Y$ et al (2019). Recent advances in understanding beta- ketothiolase (mitochondrial acetoacetyl-CoA thiolase, T2) deficiency. Journal of Human Genetics, 64(2), 99-111.

6. Nguyễn Ngọc Khánh, Vũ Chí Dũng, Bù̀i Phương Thảo và cộng sự (2015). Phát triển thể chất và tinh thần của bênh nhân thiếu betaketothiolase tại bệnh viện Nhi Trung ương trong 10 năm. Tap chí Nhi khoa, 8(2), 54-57.

7. Fukao T, Scriver C.R, Kondo $\mathbf{N}$ et al (2001). The clinical phenotype and outcome of mitochondrial acetoacetyl-CoA thiolase deficiency (beta-ketothiolase or T2 deficiency) in 26 enzymatically proved and mutation-defined patients. Molecular Genetics and Metabolism, 72(2), 109-114.

\section{NGHIÊN CỨU DIỄN BIẾN VÀ KẾT QUẢ ĐIỀU TRI CỦA CHẤN THƯO'NG SO NÃO NGUY CƠ THẤP Ở NGƯỜ'I TRƯ ỞNG THÀNH TẠI BỆNH VIÊ̂N VIÊTT ĐỨC}

\section{TÓM TẮT}

Muc tiêu: Đánh giá diễn biến và kết quả điêu tri của chấn thương sọ não nguy cơ thấp. Đối tượng và phương pháp nghiên cứu: nghiên cứu mô tả, tiến cứu tất cả các bệnh nhân trên 18 tuổi, chẩn đoán chấn thương so não nguy cơ thấp được điều trị nôi khoa tại bệnh viện Việt Đức từ tháng 5.2020 đển 12.2020. Thang điểm Glasgow outcome scale được dùng để đánh giá kết quả điêu trị. Kết quả: 306 bệnh nhân đủ điều kiện nghiên cứu. Độ tuổi trung bình: 42,07士18; tỉ lệ nam (77,78\%), nữ $(22,22 \%)$. Tai nạn giao thông là nguyên nhân chính $(81.37 \%)$. Số phim

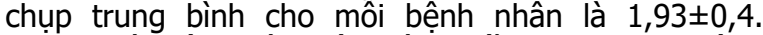
$1,96 \%$ có triệu chứng lâm sàng xấu đi. $87,21 \%$ bệnh nhân không có di chứng sau 3 tháng xuất viện. Tî lệ tử vong là $0,65 \%$. Kết luận: Điêuu trị nội khoa mang lại kết quả tốt. Tùy vào tình trạng bệnh nhân và hoàn cảnh cụ thể sẽ có chỉ định cận lâm sàng và phương án điều trị khác nhau.

\section{SUMMARY}

PROGRESSION AND SHORT TERM OUTCOMES OF MILD TRAUMATIC BRAIN INJURY IN ADULTS IN VIET-DUC HOSPITAL

Object: progression and short-term outcomes of mild traumatic brain injury in adults were studied. Patients and methods: prospective, descriptive study on nonoperative mild traumatic brain injury in adults in Viet-Duc hospital from May 2020 to December 2020. Glasgow outcome scale was used to

${ }^{1}$ Đại học Y Hà nội

Bềnh viên Viêt Đức.

Chịu trách nhiệm chính: Ngô Mạnh Hùng

Email: ngomanhhung2000@gmail.com

Ngày nhận bài: 10.5 .2021

Ngày phản biên khoa hoc: 25.6.2021

Ngày duyệt bài: 12.7 .2021 evaluate treatment outcomes. Results: 306 cases met inclusion criteria. Mean age: 42.07 \pm 18 ; male (77.78\%), female (22.22\%). Traffic accident was seen in most patients. The mean number of CT scan was $1.93 \pm 0.4$. There were 6 cases $(1.96 \%)$ witnessed clinical deterioration. Good recovery with no disability accounted for $87.21 \%$ of all patients during the 3month follow up. Mortality rate was $0.65 \%$. Conclusion: Nonoperative treatment has yielded positive results. Depending on patients's condition and specific circumstances, there will be different indications and treatment options.

\section{I. ĐĂT VẤN ĐỀ}

Chấn thương sọ não là một trong các nguyên nhân gây tử vong hàng đầu trên thế giới cũng như ở Việt nam [1-3]. Chấn thương sọ não được chia thành các nhóm nặng (GCS 3-8); trung bình (GCS 9-13) và nhe hay còn gọi là nguy cơ thấp (GCS 14-15)[4]. Trong đó CTSN nguy cơ thấp là nhóm có tình trạng lâm sàng tốt nhất, tiên lượng tốt nhất song lại ít được quan tâm hơn so với các nhóm còn lại. Mặc dù chủ đề này đã được nghiên cứu từ rất sớm ở Việt nam $[2,3,5]$, tuy nhiên điều trị và tiên lượng CTSN nguy cơ thấp vẫn còn là một trong những thách thức trên thực hành lâm sàng. Chúng tôi tiến hành nghiên cứu này với mục đích đánh giá kết quả điều trị nội khoa CTSN nguy cơ thấp tại bệnh viện Việt Đức.

\section{II. ĐỐI TƯỢNG VÀ PHƯƠNG PHÁP NGHIÊN CỨU}

Nghiên cứu mô tả, tiến cứu, theo dõi dọc được tiến hành trong thời gian từ tháng 5.2020 đến tháng 12.2020 tại khoa Phẫu thuật Thần kinh II, bệnh viện Việt Đức.

Tiêu chuẩn lựa chọn bệnh nhân: 